\title{
Survey on Technologies, uses and Challenges of IoT
}

\author{
Sandip Sonawane \\ Assistant Professor, R. C. Patel Institute of Technology, \\ Shirpur, Maharashtra, India
}

\begin{abstract}
Internet of Things (IoT) has been growing rapidly due to its importance in consumer, commercial, industrial, and infrastructure spaces. Connecting any object together through internet looks very difficult, but within a frame of time, IoT will significantly change our day to day life. The IoT is a platform where any objects can be equipped with identifying, sensing, networking and processing capabilities. It will allow them to communicate with one another and with other devices and services over the Internet to accomplish some objective. The main objective of this paper is to review various technologies as well as uses of IoT field along with its merits and demerits. As a vital improvement of the next age of Internet, the IoT pulls in numerous considerations by industry world and scholarly circles.
\end{abstract}

Keywords: Internet of Things, machine to machine, RFID, sensors, smart.

\section{INTRODUCTION}

The IoT is the network of physical objects (any things) such as devices, home appliances, machines, vehicles, buildings and other things embedded with electronics, software, sensors and network connectivity that enables these objects to collect, exchange, control and manage the data. These all things communicate via Internet. Information is gathered from various sensors, actuators and the appropriate processing takes place accordingly. This pre-processing and post processing of information is stored in the clouds. The cloud information maintenance is done by the cloud service providers. The IoT allows people and things to be connected anywhere, anytime with anyone and anything. Across various network infrastructures, IoT allows sensing of the objects and remotely access which in turn creates an opportunities for integrating real world into computerized system. IoT technologies are being implemented for agriculture development, remote machine diagnostics, manufacturing automation, healthcare and supply chain management. In this technology the devices, sensors, actuators and other objects will communicate with each other's and thereby it make our day to day life far better and easier than ever [1]

\section{IOT TECHNOLOGIES}

There are different technologies that can be used to implement the concept of IoT. In this paper, we describe the following technologies:

\section{1. RFID}

Radio Frequency Identification (RFID) is a system that transmits the identity of an object or person wirelessly using radio waves to read and capture information stored on a tag attached to an object. RFID technology plays an important role in IOT for solving identification issues and provides a unique identifier for that object. RFID system is composed of one or more RFID reader and several RFID tags. Here in this system RFID Tags uses radio-frequency electromagnetic fields to transfer data attached to an object. The tags contain electronically stored information. The RFID device serves the same purpose as a barcode or a magnetic strip on the back side of ATM card or credit card and just as a magnetic strip or bar code must be scanned to get the information, the RFID device must be scanned to retrieve the identifying information $[2,3]$.

\section{Cloud}

All the collected data or information is stored in the cloud The pre-processing and post processing of information is also stored in the clouds. The cloud information maintenance is done by the cloud service providers. To provide useful information for the end user, the gathered data is transmitted to a cloud based service where the information coming in from the IoT device is grouped with other cloud based data. IoT devices can gather data and process the gathered data either locally or send the data to centralized servers or cloud-based application back-ends for further processing $[4,5]$.

\section{Machine to Machine Communication}

Machine-to-Machine (M2M) refers to the communications between machines (computers), embedded processors, sensors, actuators and mobile devices. The use of M2M communication is increasing in the scenario at a fast pace M2M has several applications in various fields like medical, healthcare, smart robots, transportation, manufacturing systems, home automation, smart grids etc. [3].

\section{Sensors and Actuators}

When IoT is augmented with sensors and actuators, the technology becomes an instance of the more general class of cyber-physical systems, which also encompasses technologies with smart things such as smart home, smart grid, smart vehicle etc.

All IoT based systems need to have one or more sensors or actuators to gather the data from the environment. Sensors are essential components of smart objects. One of the most 
important feature of the IoT is context awareness, which is not possible without sensor technology. IoT sensors are usually small in size, have low cost, and less power consumption.

An actuator is device that converts energy into physical quantity (motion), which means actuators drive motions into mechanical systems. It takes electric current, hydraulic fluid or some other source of power. Actuators can create either linear motion, rotary motion or oscillatory motion. Actuators may cover short distances, up to 30 feet and communicate with the speed less than $1 \mathrm{Mbps}$. Actuators typically are used in industrial or manufacturing applications [6].

\section{Network Connectivity}

It allows personal computers and other physical devices to communicate over a wireless signal. Sometimes Wi-Fi technology or Wireless Sensor Network (WSN) is used to communicate the computer with physical objects. Devices that can use Wi-Fi technology include video-game consoles, smartphones, digital cameras, personal computers, tablet computers, digital audio players and modern printers. Wi-Fi enabled devices can connect directly to the Internet via a WLAN network and a wireless access point [5].

\section{Smart Cars}

\section{USES OF IOT}

Now a days, smart cars are used to improve accident prevention. These driverless cars will provide functioning more than just safety such as they can save valuable time, reduce stress of driving etc. [15].

\section{Smart Parking}

To detect the arrival and departure of vehicles the new Smart Parking sensor's or switches are used in parking spaces. The Smart parking provides extensive parking management solutions which helps motorists save time and fuel [7].

\section{3. Home and Building Automation}

Smart home becomes a most important IoT application on all measured channels. In day to day life, we are using various electronic gadgets such as microwave ovens, refrigerators, heaters, air conditioners, fan and lights. Sensors and actuators will be installed in these devices in order to utilize the energy sufficiently and also to add more comfort in life. IoT devices can be used to control and monitor the mechanical, electrical and electronic systems used in various types of areas (e.g. private and public, industrial, institutions or residential) in building automation and home automation systems [8, 9].

\section{3. Building Smart City}

Smart city covers a wide variety of use cases such as traffic management, water supply management, waste management, urban security and environmental monitoring. It's popularity is fueled by the fact that many smart city solutions promise to alleviate real pains of people living in cities these days. IoT solutions in the era of smart city solve the problem of traffic congestion, reduces the noise and pollution and helps to make cities safer [10].

\section{Smart Water Supply}

Smart cities must monitor water supply to guarantee that there is adequate access for resident and business need. Wireless Sensor Networks (WSN) provide the technology for cities to monitor their water pipeline systems more accurately and discover their greatest water loss risks. Cities that are facing water leakage problem with sensor technology are producing high savings from their investment $[16,17]$.

\section{5. Medical and Healthcare}

IoT based healthcare system can gather information about health and send the gathered information to health monitoring center. These centers can therefore examines the health and provide the valuable report and information to the individual person. The IoT has important applications in healthcare system like clinical wearables to first responder tablets, sophisticated surgical suite equipments etc. IoT devices can be used to allow the remote health monitoring [11] and emergency notification systems. These health monitoring devices can range from heart rate monitors blood pressure and $\mathrm{t}$ advanced devices capable of monitoring specialized implants, such as pacemakers or advanced hearing aids [12].

It is possible to detect heart rate of person using heart beat sensing even though the person is sitting at home [13]. Also one can detect many deadly diseases in very early stage with the help of IoT health monitoring system [14].

\section{Environmental Monitoring}

Environmental monitoring applications based on IoT, normally uses sensors to monitor the water or air quality, soil or atmospheric situations, and also include areas like monitoring the movements of wildlife and their habits [19].

\section{Transportations}

Cars or self-driving cars and intelligent transportation [18] and logistics systems are connected using IoT technology. With this technology, it is possible to minimize the traffic congestion while travelling and vehicle impact on the environment, also save the life of people from accidents and also minimize [18]. The IoT can helps in integration of communications, control, and information processing across various transportation systems.

\section{CHALLENGES OF IOT}

\section{Privacy Issues}

Privacy is the important aspect to protect the information of individuals from exposure in the IoT environment. The IoT devices will collects the user data without their permission, examines them for to known the parent company. The social embrace of the IOT devices allows the people to trust these devices with collection of their personal data without understanding the future consequences [22].

\section{Security Concerns}

Cyber attackers will use IoT devices as a potential entry points to cause harm to other devices in the network, if they are poorly secured. This will result into loss of personal data out into the public. 
Security is major concern in IoT implementation as more number of devices are being connected over the network thus there are more chances of getting our devices infected with malware. Less expensive devices have higher chances of getting tampered [21].

\section{Availability}

Availability of software denotes to the ability of the IOT applications to provide services for everyone at different places simultaneously. Availability of the IOT must be realized in the software and hardware levels to provide anytime and anywhere services for end users. Internet connectivity should be available everywhere for implementation of IoT in various areas. But in fact, even today internet connectivity is not available in most parts of the world. The IoT technology requires constant and reliable connectivity. Because of unreliable source of connectivity, lot of difficulties are being faced in IoT implementation [20].

\section{Energy Management}

Integration of systems with sensor and actuators connected to the Internet, is likely to optimize energy consumption as a whole. It is expected that IoT devices will be integrated into all forms of energy consuming devices like power outlets, televisions, switches, bulbs etc. and will be able to connect with the utility supply company in order to balance power generation and energy usage effectively [24].

\section{Inter-Operability Standard Issues}

In an ideal environment, exchange of information should take place between all the interconnected IoT devices. But the actual scenario is essentially more complex and depends on various levels of communication protocols stacks between such devices.

Connecting different systems through IoT interoperability challenges arises [23]. There is a difficulty in creating real cross-domain services for seamless movement of different data and devices. Therefore interoperability of different systems in IoT is the major concern.

\section{CONCLUSION}

The internet has significantly changed the way we lived, as in scenario all the communication is done over the Internet. IoT has the potential to add a new dimension to this process by allowing communication between smart objects. IoT should be considered as a part of future internet as everything is going to be connected in a network so that objects can interact, communicate with each other, but still there are lots of issues which are to be solved to make this a reality. Lot of research is required in this area, once implemented successfully; the quality of life is improved because of the reduction of the effort made by humans on unimportant things.

This paper presents the overview of IoT, the technologies which make the IoT to work efficiently, various challenges faced when implementing it. IoT and its services are becoming part of our everyday life. But still there are several IoT challenges related to the deployment, growth, implementation and use of this technology. The IoT involves a complex and evolving set of social, technological, and policy considerations across a diverse set of stakeholders. But it will be a helpful for every one of us in upcoming future.

\section{REFERENCES}

[1] Krishan Kumar Goyal, Amit Garg, Ankur Rastogi, Saurabh Singhal, "A Literature Survey on Internet of Things (IoT)", in International Journal of Advanced Networking and Applications, Volume 09, Issue 06, 2018, Pages: 3663-3668.

[2] Francesco Restuccia, Salvatore D'Oro and Tommaso Melodia, "Securing the Internet of Things in the Age of Machine Learning and Software-defined Networking", in IEEE Internet of Thing Journal, Vol. 1, No. 1, January 22018.

[3] Ruchi Parashar, Abid Khan and Neha, "A Survey: The Internet of Things", in International Journal of Technical Research and Applications, Volume 4, Issue 3 (May-June, 2016), PP. 251-257.

[4] Lipi Chhaya, Paawan Sharma et all, "IoT-Based Implementation of Field Area Network Using Smart Grid Communication Infrastructure", in Smart Cities 2018, 1, 176-189; doi:10.3390/smartcities1010011.

[5] Dashrath Mane and Sangita Yadav, "A Survey on Technologies, Applications and Challenges of IoT", in International Journal of Advanced Research in Computer Engineering \& Technology (IJARCET), Volume 6, Issue 6, June 2017, ISSN: 2278 - 1323.

[6] Neha Mangla, Priya Rathod, "A Comprehensive Review: Internet of Things (IOT)", in IOSR Journal of Computer Engineering (IOSR-JCE) Volume 19, Issue 4, Ver. III (Jul.-Aug. 2017), PP 62 72.

[7] Abhirup Khanna, Rishi Anand, "IoT based Smart Parking System", in International Conference on Internet of Things and Applications (IOTA), Jan 2016.

[8] Majid Al-Kuwari , Abdulrhman Ramadan et, all, "Smart-home automation using IoT-based sensing and monitoring platform", in 2018 IEEE 12th International Conference on Compatibility, Power Electronics and Power Engineering (CPE-POWERENG 2018), April 2018, DOI: 10.1109/CPE.2018.8372548

[9] Vinay sagar K N, Kusuma S M, "Home Automation Using Internet of Things", in International Research Journal of Engineering and Technology (IRJET), Volume: 02 Issue: 03,Jan-2015, PP- $1965-$ 1970.

[10] Prof. K.Adisesha, Dr.B.Lakshma Reddy, Dr. Narasaiah. B, "Implementation of IoT Technology in building Smart Cities", in International Journal of Innovative Research in Computer and Communication Engineering, Vol.5, Special Issue 2, April 2017 PP-138-145.

[11] B. N. Karthik , L. Durga Parameswari , R. Harshini , A. Akshay, "Survey on IOT \& Arduino Based Patient Health Monitoring", in International Journal of Scientific Research in Computer Science, Engineering and Information Technology, (IJSRCSEIT), Volume 3 , Issue 1 , ISSN : 2456-3307, 2018, PP-1414-1417.

[12] Arun Kumbi , Pavankumar Naik, Kirthishree C. Katti, Kiran Kotin, "A Survey Paper on Internet of Things Based Healthcare System", in Internet of Things and Cloud Computing. Special Issue: Advances in Cloud and Internet of Things. Vol. 5, No. 5-1, 2017, PP. 1-4. doi: 10.11648/j.iotcc.s.2017050501.11.

[13] Dr.A.A.Gurjar, Neha A. Sarnaik, "Heart Attack Detection By Heartbeat Sensing using Internet of Things: IoT", in International Research Journal of Engineering and Technology (IRJET), Volume: 05, Issue: 03, Mar-2018, pp-3332-3335.

[14] Akshat Savaliya, Aakash Bhatia, Jitendra Bhatia, "Application of Data Mining Techniques in IoT: A Short Review", in International Journal of Scientific Research in Science, Engineering and Technology (IJSRSET), Volume 4, Issue 2, 2018.

[15] Leelavathi T C, Dr. Shivaleelavathi B G, Shubha B, "IoT for Smart Car using Raspberry PI", in International Research Journal of Engineering and Technology (IRJET), Volume: 03, Issue: 06 , June-2016.

[16] Mourvika Shirode, Monika Adaling, Jyoti Biradar, Trupti Mate, "IOT Based Water Quality Monitoring System", in International Journal of Scientific Research in Computer Science, Engineering 
and Information Technology, (IJSRCSEIT), Volume 3, Issue 1, ISSN : 2456-3307, 2018, pp-1423-1428.

[17] Alfiya Abubaker, Kavya C R. et all, "Study on IOT Approach for Monitoring Water Quality Using MQTT Algorithm", International Research Journal of Engineering and Technology (IRJET), Volume: 05, Issue: 03, Mar-2018.

[18] P S Saarika, K. Sandhya, T. Sudha, "Smart transportation system using IoT", in 2017 International Conference On Smart Technologies For Smart Nation (SmartTechCon), Aug 2017, DOI: 10.1109/SmartTechCon.2017.8358540.

[19] Jalpa Shah, Biswajit Mishra, "IoT enabled environmental monitoring system for smart cities", in 2016 International Conference on Internet of Things and Applications (IOTA), Jan 2016, DOI: 10.1109/IOTA.2016.7562757.

[20] Anurag Shukla, Sarsij Tripathi, "A Survey on Next generation Computing IoT Issues and Challeges", in International Journal of Pure and Applied Mathematics, Volume 118, No.9, 2018, pp 4564.

[21] Muhammad Usman, Irfan Ahmed et all, "SIT: A Lightweight Encryption Algorithm for Secure Internet of Things", in International Journal of Advanced Computer Science and Applications (IJACSA), Vol. 8, No. 1, 2017.

[22] Wei Zhou, Yuqing Zhang, and Peng Liu, "The Effect of IoT New Features on Security and Privacy: New Threats, Existing Solutions, and Challenges Yet to Be Solved", National Computer Network Intrusion Protection Center, University of Chinese Academy of Sciences, Beijing, Jan 2018.

[23] Emrah Irmak, Mehmet Bozdal, "Internet of Things (IoT): The Most Up-To-Date Challenges, Architectures, Emerging Trends and Potential Opportunities", in International Journal of Computer Applications, Volume 179 - No.40, May 2018, pp 20-27.

[24] Mritunjay Kumar, Km Annoo, Raman Kumar Mandal, "The Internet of Things Applications for Challenges and Related Future Technologies \& Development", in International Research Journal of Engineering and Technology (IRJET), Volume: 05, Issue: 01, Jan-2018.

[25] Arshdeep Bahga, Vijay K. Madisetti, Raj K. Madisetti, Andrew Dugenske, "Software Defined Things in Manufacturing" in Journal of Software Engineering and Applications, 2016, 9, pp425-438.

[26] Arshdeep Bahga, Vijay K. Madisetti, "Blockchain Platform for Industrial Internet of Things Networks" in Journal of Software Engineering and Applications, 2016, 9, 533-546.

[27] Somayya Madakam, R. Ramaswamy, Siddharth Tripathi, "Internet of Things (IoT): A Literature Review", Journal of Computer and Communications, May 2015, 3, 164-173. 